\title{
Outcome of Three Neonates Born to Two Goitrous Mothers with High Levels of Thyrotropin Receptor Blocking Antibodies at the Singapore General Hospital
}

\author{
Chiaw-Ling Chng, Su Chin Ho, Daphne Hsu Chin Khoo \\ Department of Endocrinology, Singapore General Hospital
}

\begin{abstract}
Objective. We report the thyroid function of 3 neonates born to 2 goitrous mothers with high levels of thyroid binding inhibitory immunoglobulin (TBII) and TSH receptor blocking antibodies (TSBAb).

Methodology. A retrospective chart review of 3 neonates born to 2 goitrous mothers managed in a tertiary institution in Singapore.

Results. Patient A had a long-standing history of Graves' disease (GD) but developed spontaneous hypothyroidism during pregnancy. At 32 weeks, she was found to have high levels of TBII and TSBAb. The neonate had mildly elevated TSH levels for 15 weeks but serum thyroxine levels (subclinical hypothyroidism) remained normal without treatment. The patient became pregnant again 3 years later. The second offspring had TBII with strong TSBAb activity during the perinatal period but remained euthyroid. Patient B was diagnosed with primary hypothyroidism at the age of 13 . Subsequent tests revealed strong TBII and TSBAb activity. She became pregnant at age 27 and her TBII levels remained $>40 \mathrm{IU} / \mathrm{L}$ throughout pregnancy. Her offspring was born with an elevated TBII level of 22.6 IU/L (NR 0-1.5) but normal thyroid function.

Conclusion. These cases illustrate that high levels of maternal TSBAb need not necessarily result in neonatal hypothyroidism and also suggest that the maternal and fetal thyroidal responses to these antibodies may not be identical.
\end{abstract}

\section{Keywords: Graves' disease, pregnancy, blocking antibodies, neonatal hypothyroidism}

\section{Introduction}

It is well-known that 2 types of TSH receptor autoantibodies (TRAb) are associated with autoimmune thyroid diseases. Thyroid stimulating autoantibody (TSAb) is usually found in patients with Grave's Disease (GD) and TSH receptor blocking antibody (TSBAb), may be found in patients with autoimmune primary hypothyroidism..$^{1-3}$ These 2 forms of autoantibodies may also co-exist in patients with GD and the appearance of blocking antibodies can result in spontaneous remission of GD in patients or development of hypothyroid state. ${ }^{3,4}$ The emergence of blocking TRAb have been suggested by some to account for the remission of GD in pregnancy. ${ }^{5}$ Theoretically however, the presence of these autoantibodies may potentially pose a separate problem to the neonate, giving rise to transient hypothyroidism by blocking the neonatal TSH receptors.

In this case series, we report the thyroid function of 3 neonates born to 2 goitrous mothers with high levels of

ISSN 0857-1074

Printed in the Philippines

Copyright (C) 2012 by the JAFES

Received March 16, 2012. Accepted April 11, 2012.

Part of this paper has been presented as a poster at the $81^{\text {st }}$ Annual American Thyroid Association Meeting at Palm Springs, California on 26-30th October 2011
TSBAb. One neonate had transient subclinical neonatal hypothyroidism, while the other two were euthyroid, despite presence of TBII and TSBAb in all of them. This serves to highlight that the development of hypothyroidism in neonates can be unpredictable even in the face of high levels of TSBAb.

\section{Cases 1 and 2 (Patient A)}

A 32-year-old Chinese female was admitted in January 2003 for diarrhoea and vomiting. She has a history of GD with multiple relapses since 1995 due to non-compliance with treatment and follow-up. Examination during this admission revealed tachycardia of $100 / \mathrm{min}$ and a moderately enlarged diffuse goiter. Free thyroxine level (FT4) > $90 \mathrm{pmol} / \mathrm{L}$ (NR 9.6-19.1) and thyroid stimulating hormone $(\mathrm{TSH})<0.006 \mathrm{mU} / \mathrm{L}$ (NR 0.36-3.24). She was diagnosed to have GD and viral gastroenteritis. Treatment with carbimazole (CMZ) $20 \mathrm{mg}$ bid was started and switched to propylthiouracil (PTU) $200 \mathrm{mg}$ bid 2 weeks later when she was found to be pregnant at 6 weeks gestation.

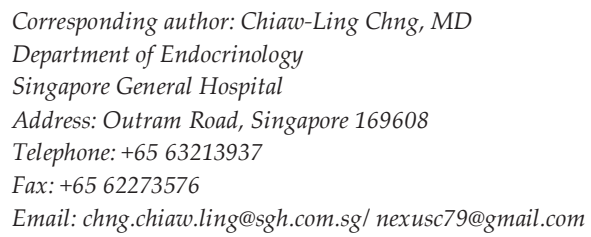




\begin{tabular}{|c|c|c|c|c|c|c|c|}
\hline Date & $\begin{array}{l}\text { Weeks of } \\
\text { gestation }\end{array}$ & $\begin{array}{c}\text { FT4 } \\
(9.6-19.1 \mathrm{pmol} / \mathrm{L})\end{array}$ & $\begin{array}{c}\text { TSH } \\
(0.36-3.34 \mathrm{mU} / \mathrm{L})\end{array}$ & $\begin{array}{c}\text { TBIII } \\
\text { TRAb } \\
(0-1.5 I U / L)\end{array}$ & $\begin{array}{c}\text { TSAb } \\
(50-179 \%)\end{array}$ & $\begin{array}{c}\text { TSBAb } \\
(71-171 \%)\end{array}$ & Medications \\
\hline 3.1 .2003 & 4 & $>90$ & $<0.006$ & & & & CMZ $20 \mathrm{mg}$ bid \\
\hline 4.2 .2003 & 8 & 13.8 & $<0.006$ & 29.7 & & & $\begin{array}{l}\text { PTU } 200 \mathrm{mg} \text { bid. PTU } \\
\text { decreased to } 100 \mathrm{mg} \text { bid }\end{array}$ \\
\hline 4.3 .2003 & 12 & 5.4 & $<0.006$ & $>40$ & & & PTU stopped \\
\hline 31.3 .2003 & 16 & 5.4 & 0.99 & $>40$ & $125 \%$ & & LT4 75 ug daily \\
\hline 28.4 .2003 & 20 & 8.2 & 0.71 & & & & LT4 75 ug daily \\
\hline 26.5 .2003 & 24 & 9.3 & 0.3 & & & & LT4 100 ug daily \\
\hline 7.7 .2003 & 30 & 10.8 & 0.029 & $>40$ & & $8.0 \%$ & LT 4100 ug daily \\
\hline 25.8 .2003 & 37 & 14.8 & 0.006 & $>40$ & & & LT4 100ug daily \\
\hline
\end{tabular}

Four weeks after the initiation of anti-thyroid drugs, her FT4 level had normalized. The thyroid antibodies showed elevation of thyrotropin receptor antibody (TRAb) 29.7 IU/L (NR 0-1.5), anti-thyroglobulin antibody (TgAb) 624.2 $\mathrm{U} / \mathrm{ml}$ (NR 0-60) and anti-thyroperoxidase antibody (TPOAb) 3000U/ml (NR 0-60). Her PTU dose was halved.

By 12 weeks gestation, her FT4 had decreased to 5.4 pmol/L and PTU was discontinued. Despite this, the FT4 remained low with normal TSH level. The patient elected to commence thyroxine (LT4) and was given LT4 $75 \mathrm{ug}$ daily (1.25ug/kg/day). Throughout her pregnancy, TRAb level remained markedly elevated with no TSAb activity. Testing of TSBAb showed strong TSH blocking activity at $8.0 \%$ (NR $71-171 \%$ ).

Our laboratory uses a bioassay that involves Chinese hamster ovary $(\mathrm{CHO})$ cell lines which are transfected with TSHR. ${ }^{6,7}$ In the bioassay to detect blocking activity (TSBAb assay), a reduction in TSH-induced cAMP is being measured. The cAMP values are expressed as a percentage inhibition (TSBAb) compared to normal serum. The normal range of $71-171 \%$ denotes no TSBAb activity and the lower the value (below the normal range), the higher the TSBAb level.

By 24 weeks, LT4 dosage was titrated up to 100ug daily to maintain euthyroidism. The child was born full term in August 2003 with TSH 34.45MU/L (NR 2-23), FT4 13.6pmol/L (NR 8.4-18.5), and total T4 113nmol/L (NR 80180). The TSH level remained mildly elevated for 15 weeks while FT4 remained within acceptable range. The TRAb level measured in the infant blood was $>40 \mathrm{IU} / \mathrm{L}$ at 3 weeks after birth, and dropped to $0.5 \mathrm{IU} / \mathrm{L} 15$ weeks later. The child had initial mild motor developmental delay at routine developmental assessment according to the patient's history, which had improved to normal at 5 months of age, although no further information was available from the pediatrician. The child is currently studying in a mainstream school at a level appropriate and expected of her age group.

The patient was continued on thyroxine replacement after the delivery of her first child and remained euthyroid. The patient conceived again in mid 2006 and was continued on thyroxine replacement. The pregnancy was uneventful and at 32 weeks, she was on LT4 150ug daily $(2.5 \mathrm{ug} / \mathrm{kg} /$ day $)$ with the following biochemistries: FT4 $=$ $13.4 \mathrm{pmol} / \mathrm{L}, \mathrm{TSH}=0.047 \mathrm{mu} / \mathrm{L}$. TRAb was $>40 \mathrm{IU} / \mathrm{L}$ and
TSBAb $=3 \%$. The second child was born at full term without complications. Cord TSH was normal at 7.24 $\mathrm{mu} / \mathrm{L}$ despite the presence of elevated TBII (>40IU/L). This time, TSBAb activity was measured in the neonate's blood and was present at 7\%. Serial FT4 and TSH levels over the next 6 weeks remained normal. No developmental delay, hypotonia or signs of clinical hypothyroidism were noted during routine follow up of her second child.
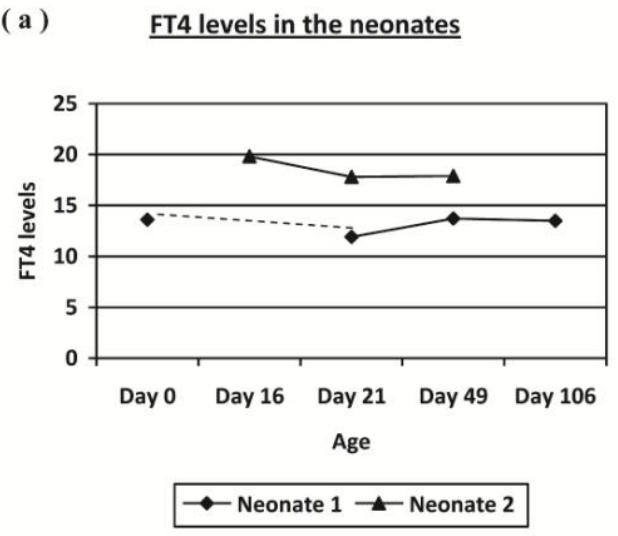

( b )

$\underline{\text { TSH levels in the neonates }}$

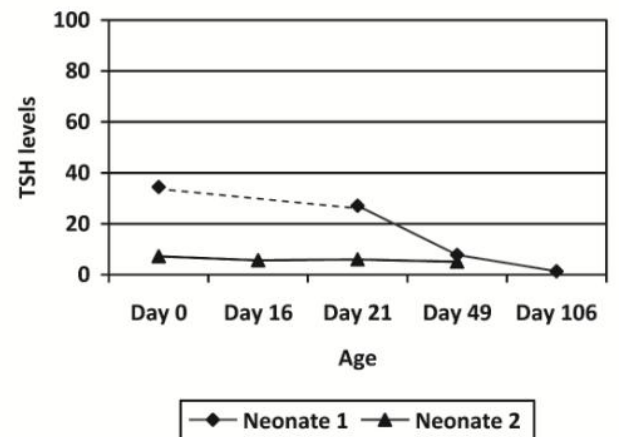

Figure 1. Graphs showing the variations of FT4 (a) and $\mathrm{TSH}$ (b) with age of the neonates born to the two pregnancies of patient $A$. Neonate 1 had transient subclinical hypothyroidism, which resolved by 15 weeks of life, accompanied by decrease in TRAb levels. Neonate 2 remained euthyroid despite presence of TSBAb in the maternal blood

\section{Case 3 (Patient B)}

This Chinese patient presented at age 13 in 1994 with classical features of hypothyroidism, a small diffuse goiter and tuberous xanthomas, associated with undetectable FT4 levels. TSH level $>100 \mathrm{mu} / \mathrm{L}$, and TBII was strongly positive at > 40 IU/L. In 1997, bioassays were carried out 
and neither TSAb nor TSBAb was present. TBII levels were measured annually and remained >40 IU/L. In 2001, TSBAb levels emerged strongly positive at $8.0 \%$ and remained positive since then. In August 2007, she became pregnant. At 36 weeks gestation, her thyroid function tests showed FT4 $15.6 \mathrm{pmol} / \mathrm{L}$, TSH $0.21 \mathrm{mU} / \mathrm{L}$ and TBII > 40IU/L. She was on thyroxine 150 ug alternating with $125 \mathrm{ug}$ daily $(2.1 \mathrm{ug} / \mathrm{kg} / \mathrm{day})$ prior to her pregnancy. The thyroxine dosage was adjusted and maintained at $125 \mathrm{ug}$ daily (1.9ug/kg/day) throughout her pregnancy. The baby was delivered via normal vaginal delivery at full term. Cord TSH was normal at $5.56 \mathrm{mU} / \mathrm{L}$, with $\mathrm{TBII}=22.6 \mathrm{IU} / \mathrm{L}$. Serial free T4, TSH measurements of the neonate over the next 6 weeks remained normal.

\section{Discussion}

Positive TRAb can be detected in $80 \%$ of newly diagnosed GD. ${ }^{8}$ These TRAb usually takes the form of stimulating antibodies in GD, although in 30\% of the cases thyroidblocking antibodies may coexist with stimulating antibodies. ${ }^{9}, 10$ Changes in thyroid antibody characteristics occurring naturally or during treatment of autoimmune thyroid disease had been observed. ${ }^{11,12}$ A change in antibody activity is usually associated with clinical remission of the hyperthyroidism or development of hypothyroidism. During pregnancy, serum levels of IgG and titers of antithyroid microsomal and antithyroglobulin antibodies have been observed to consistently decrease and then increase after delivery. ${ }^{13}$ Similar to these changes, serum levels of TSAb decrease as pregnancy advances which is accompanied by remission of thyrotoxicosis. After delivery, TSAb levels increase and are associated with postpartum relapse or aggravation of Graves' thyrotoxicosis. ${ }^{14}$

Whether a switch from TSAb to TSBAb contributes to remission of GD during pregnancy is still controversial.

A study on 15 women with GD in pregnancy demonstrated the conversion from stimulating to blocking antibodies, which resulted in clinical remission of thyrotoxicosis. ${ }^{5}$ The group observed that although the titer of TSAb decreased as pregnancy advanced, TSBAb increased in the second and third trimester of pregnancy. These results were, at variance with an earlier study by Amino et al. ${ }^{13,}{ }^{15}$ In the later study on 6 patients with Graves' disease in pregnancy, TSBAb decreased during gestation instead, followed by a clear increase after delivery. The exact reason for the disparate results between these two studies is unclear. Schwar-Lauer et al 16 pointed out the difficulty in interpreting concurrent $\mathrm{TSAb}$ and TSBAb activities in a serum as being caused by different antibodies since a weak agonist is also an antagonist. A TSAb with less intrinsic bioactivity than TSH will inhibit TSH action and demonstrate TSBAb activity. Therefore, the parallelism that we observe in $\mathrm{TSA} b$ and TSBAb activities during and after pregnancy could reflect changes in titers of the same antibody. Hence, increase in TSBAb during pregnancy may not be a general phenomenon, and amelioration of GD during pregnancy may be due to decrease in TSAb rather than increase in TSBAb. ${ }^{15}$

Maternal TSBAb causes transient hypothyroidism in the neonate via transplacental passage during pregnancy ${ }^{17-20}$ and currently accounts for $2 \%$ of all causes of congenital hypothyroidism detected during neonatal thyroid screening programs. ${ }^{21}$ This phenomenon was first proposed by Beiertwaltes and coworkers in 195922 and in 1980, Matsuura et al reported the first case of transient neonatal hypothyroidism owing to maternal TSBAb. ${ }^{18}$ This cause of neonatal hypothyroidism typically occurs in babies of mothers with the most potent TSBAb ${ }^{21}$ and is probably a likely outcome in any future pregnancy in women with these potent blocking antibodies. ${ }^{4}$ In these instances, TSBAb are found in both maternal and infant sera at birth but gradually clear from the infant's circulation after 3-4 months. This is usually accompanied by resumption of normal thyroid function. ${ }^{23}$ It is important to differentiate this group from other causes of congenital hypothyroidism as they do not require lifelong therapy. ${ }^{18-20}$ The results of thyroid imaging may be misleading in these patients, and there is a high recurrence rate in subsequent offspring due to tendency of these antibodies to persist for many years in the maternal circulation. ${ }^{18,}$ 19, 24 Diagnosis is based on demonstration of potent TRAb in either the baby's ${ }^{25}$ or mother's circulation. A study published by Rosalind et al ${ }^{21}$ found 9 babies from a total population of about 1 million babies having TSBAb induced congenital hypothyroidism. None of the infants studied by Rosalind et al developed any long-term abnormality in thyroid function despite being exposed to potent TSBAb in utero. This is consistent with the fact that TSBAb, like other IgG, does not cross the placenta until 16 weeks of gestation and therefore could not play a role in early thyroid embryogenesis. ${ }^{17}$ Since the TSBAb is of maternal origin, it declines after birth, with resolution of the neonatal hypothyroidism. The eventual development outcome of these affected neonates is unclear at this point. In a study by Kohler et al, who followed 61 infants with TSH above $50 \mathrm{mU} / \mathrm{L}$ on $5^{\text {th }}$ day of life till age $6-14 y$ rs old found no obvious impairment of growth and mental performances in the 40 infants with transient congenital hyperthyrotropinemia (raised TSH of $>50 \mathrm{mU} / \mathrm{Lwith}$ normal thyroxine levels). ${ }^{26}$

As discussed earlier, a switch in thyroid receptor antibody types during pregnancy could explain transition from hyperthyroidism to hypothyroidism we observed in Patient A. She had Graves' thyrotoxicosis at first, implying the positive TRAb was predominantly in the stimulating form. TSBAb became positive later with accompanying hypothyroidism and normal TSAb levels imply a possible switch of the antibody types during her pregnancy. The potent TSBAb present contributes to both 
maternal hypothyroidism and transient neonatal subclinical hypothyroidism via transplancetal passage in utero in her first pregnancy.

It is interesting that although the TSBAb were demonstrated in the maternal and neonatal blood in the second pregnancy, which is consistent with the fact that these potent antibodies tend to persist for many years, this child did not demonstrate any thyroid dysfunction on follow up. Another point is that although TSBAb has the potential to act on neonatal thyroid like in her first pregnancy, it did not. This phenomenon was also observed in the Patient B who had potent TSBAb.

It is unknown to date why this phenomenon occurs, but we would like to suggest a few possible mechanisms:

1. An inherent protective mechanism may be present in the fetal immune system to prevent the fetal thyroid from being affected by the maternal TSBAb such that a critical level of TSBAb titer is required to produce hypothyroidism in the child. ${ }^{4}$

2. Earlier studies of thyroid functions in fetuses during normal pregnancies have suggested an incomplete responsiveness of the fetal thyroid gland to TSH, while the feedback control system between pituitary and thyroid operates at a different set point from that in post-natal life. ${ }^{27,} 28 \mathrm{It}$ may be possible that the fetal thyroid may have reduced responsiveness to TSBAb, which acts on TSH receptors.

3. Both TSBAb and TSAb coexist in the maternal circulation and both are transmitted to the fetus, depending on the predominant type, the neonate may be euthyroid, hypothyroid or hyperthyroid, the proportions of each antibody may differ with each pregnancy, as in the first patient.

\section{Conclusion}

These cases challenge the common belief that potent maternal TRAb or more specifically, TSBAb can result in neonatal hypothyroidism via transplacental passage and also suggest that the maternal and fetal thyroidal responses to these antibodies may not be identical. However, more large scale studies are needed to confirm our findings.

\section{References}

1. Zakarija M, McKenzie JM. The spectrum and significance of autoantibodies reacting with the thyrotropin receptor. Endocrinol Metab Clin North Am 1987;16:343-63.

2. McGregor AM. Autoantibodies to the TSH receptor in patients with autoimmune thyroid disease. Clin Endocrinol (Oxf) 1990;33:683-5.

3. Rees Smith B, McLachlan SM, Furmaniak J. Autoantibodies to the thyrotropin receptor. Endocr Rev 1988;9:106-21.

4. Zakarija M, McKenzie JM, Eidson MS. Transient neonatal hypothyroidism: Characterization of maternal antibodies to the thyrotropin receptor. J Clin Endocrinol Metab 1990;70:1239-46.

5. Kung AW, Jones BM. A change from stimulatory to blocking antibody activity in Graves' disease during pregnancy. J Clin Endocrinol Metab 1998;83:514-8.

6. Kraiem Z, Lahat N, Glaser B, Baron E, Sadeh O, Sheinfeld M. Thyrotrophin receptor blocking antibodies: Incidence, characterization and in-vitro synthesis. Clin Endocrinol (Oxf) 1987;27:409-21.

7. Sato K, Okamura K, Yoshinari M et al. Goitrous hypothyroidism with blocking or stimulating thyrotropin binding inhibitor immunoglobulins. J Clin Endocrinol Metab 1990;71:855-60.

8. Gauna A, Segura G, Sartorio G, Soto R, Segal-Eiras A. Immunological aspects of Graves' disease patients in different clinical stages. J Endocrinol Invest 1989;12:671-7.

9. Tada H, Izumi Y, Watanabe $\mathrm{Y}$ et al. Blocking type anti-TSH receptor antibodies detected by radioreceptor assay in Graves' disease. Endocr J 2001;48:703-10.

10. Tada H, Mizuta I, Takano $\mathrm{T}$ et al. Blocking-type anti-TSH receptor antibodies and relation to responsiveness to antithyroid drug therapy and remission in Graves' disease. Clin Endocrinol (Oxf) 2003;58:4038

11. Kraiem Z, Baron E, Kahana L, Sadeh O, Sheinfeld M. Changes in stimulating and blocking TSH receptor antibodies in a patient undergoing three cycles of transition from hypo to hyper-thyroidism and back to hypothyroidism. Clin Endocrinol (Oxf) 1992;36:211-4.

12. Weetman AP, McGregor AM. Autoimmune thyroid disease: Further developments in our understanding. Endocr Rev 1994;15:788-830.

13. Amino N, Kuro R, Tanizawa O et al. Changes of serum anti-thyroid antibodies during and after pregnancy in autoimmune thyroid diseases. Clin Exp Immunol 1978;31:30-7.

14. Hidaka Y, Tamaki H, Iwatani Y, Tada H, Mitsuda N, Amino N. Prediction of post-partum Graves' thyrotoxicosis by measurement of thyroid stimulating antibody in early pregnancy. Clin Endocrinol (Oxf) 1994;41:15-20.

15. Amino N, Izumi $Y$, Hidaka $Y$ et al. No increase of blocking type antithyrotropin receptor antibodies during pregnancy in patients with Graves' disease. J Clin Endocrinol Metab 2003;88:5871-4.

16. Schwarz-Lauer L, Chazenbalk GD, McLachlan SM, Ochi Y, Nagayama Y, Rapoport B. Evidence for a simplified view of autoantibody interactions with the thyrotropin receptor. Thyroid 2002;12:115-20.

17. McKenzie JM, Zakarija M. Fetal and neonatal hyperthyroidism and hypothyroidism due to maternal TSH receptor antibodies. Thyroid 1992;2:155-9.

18. Matsuura N, Yamada Y, Nohara Y et al. Familial neonatal transient hypothyroidism due to maternal TSH-binding inhibitor immunoglobulins. N Engl J Med 1980;303:738-41.

19. Connors $\mathrm{MH}$, Styne DM. Transient neonatal 'athyreosis' resulting from thyrotropin-binding inhibitory immunoglobulins. Pediatrics 1986;78:287-90.

20. Francis G, Riley W. Congenital familial transient hypothyroidism secondary to transplacental thyrotropin-blocking autoantibodies. Am J Dis Child 1987;141:1081-3.

21. Brown RS, Bellisario RL, Botero D et al. Incidence of transient congenital hypothyroidism due to maternal thyrotropin receptorblocking antibodies in over one million babies. J Clin Endocrinol Metab 1996;81:1147-51.

22. Beierwaltes WH, Dodson VN, Wheeler AH. Thyroid autoantibodies in the families of cretins. J Clin Endocrinol Metab 1959;19:179-82.

23. Evans C, Jordan NJ, Owens G, Bradley D, Ludgate M, John R. Potent thyrotrophin receptor-blocking antibodies: A cause of transient congenital hypothyroidism and delayed thyroid development. Eur J Endocrinol 2004;150:265-8.

24. Goldsmith RE, McAdams AJ, Larsen PR, McKenzie M, Hess E Familial autoimmune thyroiditis: maternal-fetal relationship and the role of generalized autoimmunity. J Clin Endocrinol Metab 1973;37:265-75.

25. Brown RS, Bellisario RL, Mitchell E, Keating P, Botero D. Detection of thyrotropin binding inhibitory activity in neonatal blood spots. J Clin Endocrinol Metab 1993;77:1005-8.

26. Kohler B, Schnabel D, Biebermann H, Gruters A. Transient congenital hypothyroidism and hyperthyrotropinemia: Normal thyroid function and physical development at the ages of 6-14 years. J Clin Endocrinol Metab 1996;81:1563-7.

27. Radunovic N, Dumez Y, Nastic D, Mandelbrot L, Dommergues M. Thyroid function in fetus and mother during the second half of normal pregnancy. Biol Neonate 1991;59:139-48.

28. Ballabio M, Nicolini U, Jowett T, Ruiz de Elvira MC, Ekins RP, Rodeck $\mathrm{CH}$. Maturation of thyroid function in normal human foetuses. Clin Endocrinol (Oxf) 1989;31:565-71. 